Document downloaded from:

http://hdl.handle.net/10251/97804

This paper must be cited as:

Ruiz Martinez, A.; Serralta Sevilla, J.; Seco Torrecillas, A.; Ferrer, J. (2016). Behavior of mixed Chlorophyceae cultures under prolonged dark exposure. Respiration rate modeling. Ecological Engineering. 91:265-269. doi:10.1016/j.ecoleng.2016.02.025

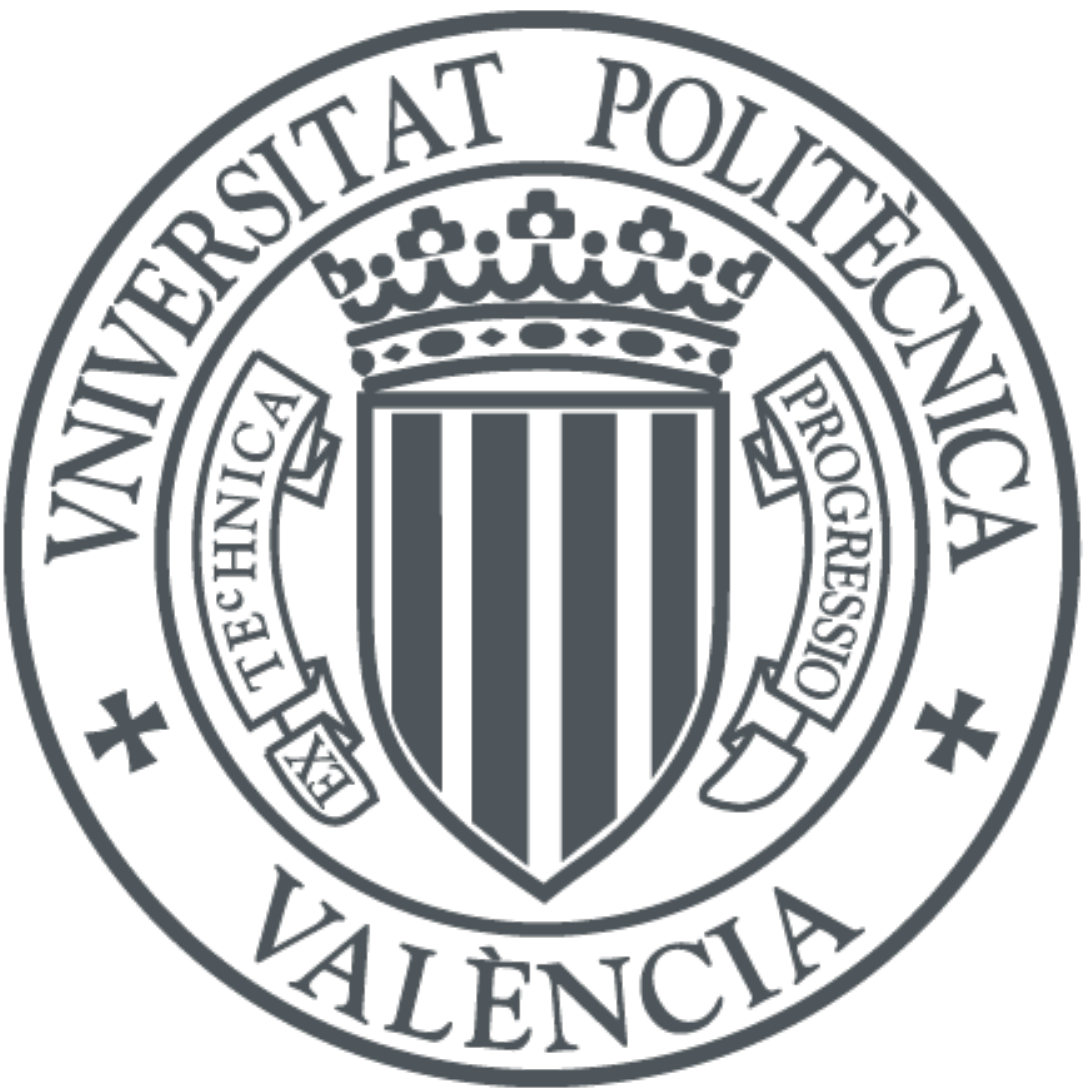

The final publication is available at

http://doi.org/10.1016/j.ecoleng.2016.02.025

Copyright Elsevier

Additional Information 


\title{
Behavior of mixed Chlorophyceae cultures under prolonged dark exposure. Respiration rate modeling.
}

\author{
Ruiz-Martínez, A.*,a, Serralta, J. ${ }^{\text {a }}$, Seco, A. ${ }^{\text {, }}$, and Ferrer, J. ${ }^{\text {a }}$ \\ anstituto de Ingeniería del Agua y Medio Ambiente, IIAMA, Universitat Politècnica de \\ Valencia, Camino de Vera s/n, 46022 Valencia, Spain (e-mail: anruima1@upv.es, \\ jserralt@hma.upv.es, jferrer@hma.upv.es)
}

bDepartamentd’Enginyeria Química, EscolaTècnica Superior d’Enginyeria, Universitat de València, Avinguda de la Universitat s/n. 46100 Burjassot, Valencia, Spain (email: aurora.seco@uv.es)

*Corresponding author. Tel. +34 963877000 ext. 76176; Fax +34 963877 618, e-mail address: anruima1@upv.es

\begin{abstract}
The behavior of three different microalgal cultures, when exposed for a long period (>48 h) to dark conditions, was studied with a methodology based on respirometry. The cultures were transferred to darkness and the oxygen evolution in the reactors was monitored after successive air injections. Several sequential oxygen uptake rates were thus calculated and a respiration constant, assuming a first order decay of a fraction of the biomass, was obtained by calibration. Initial specific oxygen uptake rates were in the range of 0.9-5.1 $\mathrm{mg} \mathrm{O}_{2} \cdot \mathrm{g} \mathrm{TSS}^{-1} \cdot \mathrm{h}^{-1}$ and dark respiration constants in the range of $0.005-0.018 \mathrm{~h}^{-1}$.
\end{abstract}

\section{Keywords}

Decay; microalgae; modeling; respiration. 


\section{INTRODUCTION}

Interest in microalgae has risen in the last decade due to the potential these microorganisms have on fighting climate change (Kumar et al., 2011), producing renewable biofuels (Parmar et al., 2011) and removing pollutants from wastewater (Rawat and Kumar, 2010).

Predicting the behavior of microalgal cultures is a very complex task, especially when outdoor conditions (variable light and temperature) and operational conditions (light attenuation, photobioreactor dimensions, hydrodynamics, etc.) should be taken into account. However, the wider the knowledge about microalgal behavior and the ability to predict it, the easier it will be to optimize their cultivation and to fully develop their potential.

Different approaches have been taken to model algal growth. Many models were developed in order to represent the behavior of microalgae in rivers and lakes (Buzzelli et al., 2014; Reichert et al., 2001; Muylaert et al., 2005). Other models have been developed in order to predict metabolites production (lipids, carbohydrates, substances of interest, etc.) (Adesanya et al., 2014; Mairet et al., 2011; Packer et al., 2011). Some authors have also taken into account physical phenomena such as variable light and temperature, mixing, or gas transfer. (García-Camacho et al., 2012; Pegallapati and Nirmalakhandan, 2012; Vunjak-Novakovic et al., 2005).

When microalgae are cultivated in closed photobioreactors, microalgal biomass density increases and, due to selfshading, a fraction of the culture cannot receive the amount of light required for photosynthesis. This fact makes it necessary to take respiration losses into account, since they will be the dominant metabolic activity in the dark regions. This will also be the case for the whole culture during dark periods (nights) and inside dark 
plant elements. In these cases, microalgal growth in the reactor will cease and therefore biomass loss will take place. Under optimal conditions, respiration rates are about 20-30 $\%$ of growth rates, but the ratio of respiration to growth increases under suboptimal conditions (Geider and Osborne, 1989). Several authors report respiration losses of 210\% of biomass in outdoor cultivation systems (Kethesaan and Nirmalakhandan, 2013), although losses of up to $35 \%$ of the biomass have been reported during nighttime (Vonshak, 1987, for Spirulina).

When modeling microalgal growth there is usually a hidden term in the "net" growth rate which accounts for some dark respiration losses. Indeed, a fraction of respiration losses is proportional to microalgal growth. This fraction corresponds to the cost of biosynthesis: ion uptake, transformation of ions into intermediates, synthesis of cell structural and functional metabolites, etc. The other term which contributes to respiration losses is the maintenance metabolic costs (also called basal respiration: motility, volume regulation, turnover of macromolecules). These costs are, by definition, independent of growth and proportional to biomass (Geider et al., 1998).

Knowing the rate of microalgal respiration in the dark is important for microalgal growth modeling under outdoor conditions, since biomass production and net carbon balance are affected by day/night cycles and by the volume fraction of the photoreactors which is in the dark (Bernard, 2011). This affects the economic and environmental balance of the system. Moreover, gaining knowledge on the behavior of microalgae under prolonged exposure to dark will help designing other wastewater treatment systems with opaque modules such as those for microalgae storage, filtration, etc.

The aim of this work was to study the behavior of different microalgal cultures during prolonged exposure to darkness ( $>48 \mathrm{~h}$ ). To our knowledge, no such long exposures 
have been previously studied. Based on dissolved oxygen measurements (respirometry), a methodology was developed to obtain the associated respiration rate. A comparison of the behavior of the cultures and a possible explanation for the differences among them is also given.

\section{MATERIALS AND METHODS}

\subsection{Microorganisms}

Three different types of microalgae cultures were studied. Microalgae had previously been isolated from the walls of the secondary clarifier in the "Cuenca del Carraixet” WWTP (Valencia, Spain) and maintained as a mixed autochthonous culture in the laboratory in $7 \mathrm{l}$ semicontinuous reactors (for a more detailed explanation of the reactors setup see Ruiz-Martinez et al., 2012). The effluent of a submerged anaerobic membrane bioreactor (SAnMBR, described in Giménez et al., 2011) was used as growth medium.

The cultures used in the experiments were the following:

- $\quad$ Dark kept culture (DC): this culture was stored in a dark fridge $\left(8^{\circ} \mathrm{C}\right)$ for 15 days previous to the respirometric study. The culture was allowed to increase temperature until reaching $20^{\circ} \mathrm{C}$ during 12 hours prior to the respirometry. It consisted of a mixed culture of microalgae dominated by the class Chlorophyceae.

- $\quad$ Nutrient limited culture (LC): this culture was the accumulated purge of a semicontinuous reactor kept under laboratory conditions as explained above. The purge was accumulated in a translucent container with no agitation nor $\mathrm{CO}_{2}$ addition. pH did not increase higher than 8 . The respirometric study started $48 \mathrm{~h}$ 
after nutrient depletion, a total of $96 \mathrm{~h}$ after being purged from the reactor. The microalgae present were Chlorophyceae, of which $>99 \%$ from the Chlorococcales order.

- $\quad$ Replete culture (RC): this culture was directly taken from a running semicontinuous reactor and placed under dark conditions immediately. The microalgae present were Chlorophyceae, of which $>99 \%$ from the Chlorococcales order.

\subsection{Experimental setup and operation}

The experiments were carried out in three photobioreactors (PBRs). Each PBR consisted of a cylindrical, transparent methacrylate tank (20 cm internal diameter) with total and working volumes of 10 and 7 l, respectively. The PBRs were (not hermetically) sealed and they were kept in the dark in a climatic chamber with a temperature set point of $20^{\circ} \mathrm{C}$. A pH probe connected to a multiparametric analyzer (CONSORT C832, Belgium) recorded the $\mathrm{pH}$ in the reactors, which ranged in all cases between 7 and 8.4.

Under the above mentioned conditions photosynthesis could not take place and only respiration (oxygen consumption for maintenance) occurred. Dissolved oxygen concentration (DO) was measured using a Cellox 325 electrode (WTW, Germany) connected to an oximeter (Oxi 320, SET WTW, Germany). The measured dissolved oxygen values were logged in a PC using data acquisition software. Ambient air was injected at a flow rate of $0.8-1.0 \mathrm{l} \cdot \mathrm{min}^{-1}$ through four fine bubble diffusers mounted at the bottom whenever DO concentration was below $1 \mathrm{mg} \mathrm{O}_{2} \cdot \mathrm{l}^{-1}$ until it reached again a concentration of $6 \mathrm{mg} \mathrm{O} \mathrm{O}_{2} \cdot \mathrm{I}^{-1}$. 
The experiments were programmed to last $50 \mathrm{~h}$. However, in view of the results (see section 3) in the case of LC it was prolonged until $200 \mathrm{~h}$ and in the case of RC until 600 h.

\subsection{Analytical Methods}

Ammonium and phosphate were determined according to Standard Methods (APHA 2005) (4500-NH3-G and 4500-P-F, respectively) in a Smartchem 200 automatic analyzer (Westco Scientific Instruments, Westco). Total suspended solids (TSS) were determined according to Standard Methods (APHA 2005). All analyses were conducted in duplicate.

\section{RESULTS AND DISCUSSION}

\subsection{Dissolved Oxygen Measurements and Respiration Rates}

The time evolution of dissolved oxygen concentrations was obtained for the three experiments (figures 1a, b and c). Due to microalgal consumption in the dark, oxygen concentration decreased linearly after each air addition until it reached $1 \mathrm{mg} \mathrm{O}_{2} \cdot \mathrm{l}^{-1}$ and the aeration was switched on again. Successive Oxygen Uptake Rates (OUR, mg $\mathrm{O}_{2} \cdot \mathrm{l}^{-}$

$\left.{ }^{1} \cdot \mathrm{h}^{-1}\right)$ were calculated as linear regressions $\left(\mathrm{R}^{2}>0.95\right.$ for all) of these decreasing stretches (figure 1a). Due to the aeration, the DO concentration increased up to $6 \mathrm{mg}$ $\mathrm{O}_{2} \cdot \mathrm{l}^{-1}$, and then the blower was switched off. A significant decrease was observed in most cases immediately afterwards (first 10 minutes). This corresponded to the reestablishing of the equilibrium and had been previously observed in blank reactors with only tap water (data not shown). 
Successive OURs became smaller with time, which means that endogenous respiration declined in all cases. This showed that, due to the adverse environmental conditions (darkness, absence of nutrients) and the consumption of microalgal reserves, the metabolic activity decreased. The calculated OURs $\left(\mathrm{mg} \mathrm{O}_{2} \cdot \mathrm{l}^{-1} \cdot \mathrm{h}^{-1}\right)$ during each experiment are represented in figure 2 versus time. It can be appreciated that the OUR values did not decrease linearly with time. Instead, they decreased exponentially, approaching a stable value in the long term (hence the prolonged experiment time for LC and RC).

At the beginning of the experiments, the OURs were $0.75 \mathrm{mg} \mathrm{O}_{2} \cdot \mathrm{l}^{-1} \cdot \mathrm{h}^{-1}$ for DC and RC, and $1 \mathrm{mg} \mathrm{O}{ }_{2} \cdot \mathrm{l}^{-1} \cdot \mathrm{h}^{-1}$ for LC. These values are however not directly comparable, due to the different TSS in the cultures. For comparison, TSS were measured in each reactor at $t=0$ of each experiment, allowing the calculation of the specific respiration rate. Results are shown in table I: specific respiration rate was highest for LC and similar values were obtained for DC and RC.

Respiration rates depend on the physiological state of the culture (growth state, age of the culture) and environmental conditions (nutrients, cell content, light intensity, temperature) (Geider, 1989). For instance, Grobbelaar and Soeder (1985) reported lower respiration rates after growth at optimal temperature than at other temperatures, and after growth under weaker illumination than under stronger irradiations. Ogbonna and Tanaka (1996) also found that microalgae with higher cell carbohydrate content showed higher biomass loss during the night.

The values obtained in this study are in accordance with the range obtained by Grobbelar and Soeder (1985). The lowest value corresponded to RC, the replete or "healthiest" culture, whereas the highest value corresponded to LC, the culture which 
was subject to nutrient stress and higher light (lower biomass concentration and therefore less selfshading results in higher light). A similar value was obtained for DC, the culture which, although it had been exposed to very dim light, was in the worst state regarding nutrient levels at the beginning of the respirometry.

Oxygen consumption of the microalgal cultures during the first hours after dark exposure (for instance, 12 hours of darkness in outdoor nights) can be estimated from the results of this study. Assuming that there is no microalgal growth during a long dark period, the COD balance indicates that the oxygen consumption rate is equal to the biomass COD loss. Therefore, the culture RC would present the smaller night COD loss: $11 \mathrm{mg} \mathrm{COD} \cdot \mathrm{g} \mathrm{TSS}^{-1}$, the culture DC would present a loss of $16 \mathrm{mg} \mathrm{COD} \cdot \mathrm{g} \mathrm{TSS}^{-1}$, and cultures under nutrient limiting conditions would loose around $61 \mathrm{mg}$ COD·g TSS${ }^{-}$ ${ }^{1}$, which could represent between 3 and $4 \%$ of the biomass. This depends on the biomass composition, since lipids, proteins and carbohydrates have different COD/TSS ratios and therefore their degradation results in different TSS losses for the same COD loss.

The resistance stage in which the culture entered allowed the microalgae to keep their photosynthetic capacity until the end of the respirometric experiment: a rapid increase in dissolved oxygen was observed when the light was switched on at the end of the three experiments (data not shown). This described survival strategy is in accordance with previous observations (Myers and Cramer, 1947; Geider et al., 1998) although not such long exposures to dark had been reported up to date.

\subsection{Data fit and calibration}

During endogenous respiration, microalgae catabolize accumulated metabolites, usually carbohydrates (Geider and Osborne, 1989; Ogbonna and Tanaka, 1996). Due to the 
observed OURs (figure 2), and in agreement with literature (Buehner et al., 2009), in this study an exponential decay of biomass was assumed:

$\frac{d x}{d t}=-k_{r} \cdot x$

where $\mathrm{x}$ represents the biomass, expressed in $\mathrm{mg} \mathrm{COD} \cdot \mathrm{l}^{-1}$ and $k_{\mathrm{r}}\left(\mathrm{h}^{-1}\right)$ is the respiration constant.

And since biomass decay equals the oxygen consumption rate:

$\frac{d x}{d t}=-k_{r} \cdot x=\frac{d O_{2}}{d t}$

The combination and integration of equations 1 and 2 renders:

$\exp \left(-k_{r} \cdot t\right)=\frac{\left[\frac{d O_{2}}{d t}\right]_{t}}{\left[\frac{d O_{2}}{d t}\right]_{0}}$

which enabled the reproduction of the obtained data (figures 3a, b and c) and determine with a good fit ( $\mathrm{R}^{2}>0.9$ in all cases) the respiration constant $k_{\mathrm{r}}$ for each culture (table I). An ANOVA analysis (carried out using SPSS 16.1) of the three sets of data represented in figures 3a, b and c confirmed the difference $(\mathrm{P}$-value $<0.05)$ among the cultures (2 degrees of freedom, F value 3.33).

The obtained $k_{\mathrm{r}}$ values were, as expected, different for each culture. Other authors have determined smaller $\left(0.006 \mathrm{~h}^{-1}\right.$ for Nannochloropsis by Hueseman et al., 2013; $0.0004 \mathrm{~h}^{-1}$ for Chlorella by Decostere et al., 2013), similar $\left(0.015 \mathrm{~h}^{-1}\right.$ for Nannochloropsis and Scenedesmus by Pegallapati and Nirmalakhandan, 2012) and higher (Sciandra, 1985 obtained a range of $0.006-0.03 \mathrm{~h}^{-1}$ for Phaeodactylum) respiration constants.

A higher respiration rate (DC) means a faster decrease in the OUR values consecutively measured, and a lower respiration rate achieved after a set amount of time. A smaller 
respiration rate $(\mathrm{RC})$ means a more stable value of the consecutive OURs measured, which become smaller with time but at a much slower speed.

\section{CONCLUSIONS}

In this study specific dark respiration rates were obtained for three different microalgal cultures by measuring dissolved oxygen evolution after being transferred to darkness. The smallest specific respiration rate $\left(0.9 \mathrm{mg} \mathrm{O} \cdot \mathrm{g} \mathrm{TSS}^{-1} \cdot \mathrm{h}^{-1}\right)$ was obtained for a fresh and nutrient replete Chlorophyceae culture, whereas the highest specific respiration rate (5.1 $\mathrm{mg} \mathrm{O}_{2} \cdot \mathrm{g} \mathrm{TSS}^{-1} \cdot \mathrm{h}^{-1}$ ) corresponded to a nutrient limited culture previously grown under continuous illumination. The methodology used proved useful for the calibration of an exponential decay equation and obtention of the respiration constants for each case, which ranged from $0.005 \mathrm{~h}^{-1}$ to $0.018 \mathrm{~h}^{-1}$. The accuracy of current basic models which otherwise do not take respiration into account could be improved by including this decay equation and determining the corresponding respiration constant.

\section{ACKNOWLEDGEMENTS}

This research work has been supported by the Spanish Ministry of Economy and Competitiveness (MINECO, CTM2011-28595-C02-01/02) jointly with the European Regional Development Fund (ERDF) which are gratefully acknowledged. This research was also supported by the Spanish Ministry of Science and Innovation via a pre doctoral FPU fellowship to the first author (AP2009-4903). The authors would also like to thank the water management entities of the Generalitat Valenciana (EPSAR).

\section{REFERENCES}


Adesanya, V.O., Davey, M.P., Scott, S.S., Smith, A.G. 2014. Kinetic modelling of growth and storage molecule production in microalgae under mixotrophic and autotrophic conditions. Bioresour Technol 157:293-304.

APHA. 2005. Standard methods for the examination of water and wastewater, 20th ed. Washington: American Public Health Association.

Bernard, O. 2011. Hurdles and challenges for modelling and control of microalgae for $\mathrm{CO}_{2}$ mitigation and biofuel production. Journal of Process Control 21 (10), 1378-1389.

Buehner, M.R., Young, P.M., Willson, B., Rausen, D., Schoonover, R., Babbitt, G., and Bunch, S. 2009. Microalgae Growth Modeling and Control for a Vertical Flat Panel Photobioreactor. American Control Conference, Hyatt Regency Riverfront, St. Louis, MO, USA, June 10-12, 2009.

Buzzeli, C., Doering, P.H., Wan, Y., Sun, D., Fugate, D. 2014. Modeling ecosystem processes with variable freshwater inflow to the Caloosahatchee River Estuary, southwest Florida. I. Model development. Estuarine, Coastal Shelf Sci 151:256-271.

Decostere, B., Janssens, N., Alvarado, A., Maere, T., Goethals, P., Van Hulle, S.W.H., Nopens, I. 2013. A combined respirometer-titrimeter for the determination of microalgae kinetics: Experimental data collection and modelling. Chem Eng J 222:8593.

Garcia-Camacho, F., Sánchez-Mirón, A., Molina-Grima, E., Camacho-Rubio, F., Merchuck, J.C. 2012. A mechanistic model of photosynthesis in microalgae including photoacclimation dynamics. J Theor biol 304:1-15.

Geider, R., Osborne, B.A. 1989. Respiration and microalgal growth: a review of the quantitative relationship between dark respiration and growth. New Phytol 112:327341.

Geider, R.J., MacIntyre, H.L., Kana, T.M. 1998. A dynamic regulatory model of phytoplanktonic acclimation to light, nutrients, and temperature. Limnol Oceanogr 43:679-694.

Giménez, J.B., Robles, A., Carretero, L., Duran, F., Ruano, M.V., Gatti, M.N., Ribes, J., Ferrer, J., Seco, A. 2011. Experimental study of the anaerobic urban wastewater 
treatment in a submerged hollow-fibre membrane bioreactor at pilot scale. Bioresour Technol 102:8799-8806.

Grobbelaar JU., Soeder, C.J. 1985. Respiration losses in planktonic green algae cultivated in raceway ponds. J Plankton Res 7:497-506.

Hueseman, M.H., Van Wagenen, J., Miller, T., Chavis, A., Hobbs, S., Crowe, B. 2013. A Screening Model to Predict Microalgae Biomass Growth in Photobioreactors and Raceway Ponds. Biotechnol Bioeng 110 (6):1583-1594.

Ketheesan, B., Nirmalakhandan, N. 2013. Modeling microalgal growth in an airliftdriven raceway reactor Bioresour Technol 136:689-696.

Kumar K, Dasgupta CN, Nayak B, Lindblad P, Das D. 2011. Development of suitable photobioreactors for $\mathrm{CO} 2$ sequestration addressing global warming using green algae and cyanobacteria. Bioresour Technol 102(8):4945-4953.

Mairet, F., Bernard, O., Masci, P., Lacour T., Sciandra, A. 2011. Modelling neutral lipid production by the microalga Isochrysis aff. galbana under nitrogen limitation. Bioresour Technol 102:142-149.

Muylaert, K., Tackx, M., Vyverman, W. 2005. Phytoplankton growth rates in the freshwater tidal reaches of the Schelde Estuary (Belgium) estimated using a simple light-limited primary production model. Hydrobiologia 540:127-140.

Myers, J., Cramer, M. 1948. Metabolic conditions in Chlorella. J gen physiol 32 (1):103-110.

Ogbonna, J.C., Tanaka, H. 1996. Night biomass loss and changes in biochemical composition of cells during light/dark cyclic culture of Chlorella pyrenoidosa. J Ferment Bioeng 82 (6):558-564.

Packer, A., Li, Y., Andersen, T., Hu, Q., Kuang, Y., Sommerfeld, M. 2011. Growth and neutral lipid synthesis in green microalgae: A mathematical model. Bioresour Technol 102:111-117.

Parmar A, Singh NK, Pandey A, Gnansounou E, Madamwar D. 2011. Cyanobacteria and microalgae: a positive prospect for biofuels. Bioresour Technol 102(22):1016310172. 
Pegallapati, A.K., Nirmalakhandan, N. 2012. Modeling Algal Growth in Bubble Columns under Sparging with $\mathrm{CO}_{2}$-enriched Air. Bioresour Technol 124:137-145.

Rawat, I., Ranjith Kumar, R. 2010. Dual role of microalgae: Phycoremediation of domestic wastewater and biomass production for sustainable biofuels production. Appl Energ 88, 3411-3424.

Reichert, P., Borchardt, D., Henze, M., Rauch, W., Shanahan, P., Somlyódy, L., Vanrolleghem, P. 2001. River Water Quality Model no. 1 (RWQM1): II. Biochemical process equations. Water Sci Technol 43 (5):11-30.

Ruiz-Martinez, A., Martin Garcia, N., Romero, I., Seco, A., Ferrer, J. 2012. Microalgae cultivation in wastewater: Nutrient removal from anaerobic membrane bioreactor effluent. Bioresour Technol 126:247-253.

Sciandra, A. 1986. Study and modelling of a simple planktonic system reconstituted in an experimental microcosm. Ecol Model 34:61-82.

Vonshak A. 1987. Mass production of Spirulina: an overview. In Biotecnologie per la produzione di Spirulina. Rome: ed. L.Tomaselli. pp. 9-14.

Vunjak-Novakovic, G., Kim, Y., Wu, X., Berzin, I., Merchuk, J.C. 2005. Air-Lift Bioreactors for Algal Growth on Flue Gas: Mathematical Modeling and Pilot-Plant Studies. Ind Eng Chem Res 44:6154-6163. 


\section{TABLE I}

Table I: Initial specific respiration rates and obtained respiration constants for the three cultures

Dark Culture Limited Culture Replete culture

$\begin{array}{llll}\text { Initial TSS (mgTSS } \cdot \mathbf{1}^{-1} \text { ) } & 588 & 206\end{array}$

Initial dark respiration rate

$$
\left(\mathrm{mg} \mathrm{O}_{2} \cdot \mathrm{g} \mathrm{TSS}^{-1} \cdot \mathrm{h}^{-1}\right)
$$

$\begin{array}{lll}1.3 & 5.1 & 0.9\end{array}$

$\begin{array}{llll}\mathbf{k r}\left(\mathbf{h}^{-1}\right) & 0.018 & 0.014 & 0.005\end{array}$




\section{FIGURE LEGENDS}

Fig 1: Dissolved Oxygen concentration during the experiments. DC (a), LC (b) and RC (c)

Fig 2: OURs (mg O $\left.{ }_{2} \cdot \mathrm{l}^{-1} \cdot \mathrm{h}^{-1}\right)$ measured over time in DC, LC and RC systems.

Fig 3: Data fit to equation 3 for DC (a), LC (b) and RC (c) 